\title{
POTENTIAL OF RAMAN LIDAR FOR PROFILING OF METHANE MIXING RATIO IN THE LOWER TROPOSPHERE.
}

\author{
Igor Veselovskii ${ }^{1}$, Philippe Goloub ${ }^{2}$, Qiaoyun $\mathrm{Hu}^{2}$, Thierry Podvin ${ }^{2}$, Mikhail Korenskiy ${ }^{1}$ \\ ${ }^{I}$ Prokhorov General Physics Institute, Moscow, Russia \\ ${ }^{2}$ Univ. Lille, Laboratoire d'Optique Atmosphérique, Lille, France
}

\begin{abstract}
The results of methane profiling in the lower troposphere by Raman lidar from Lille University observatory platform (France), are presented. The use of powerful DPSS tripled Nd:YAG laser allowed profiling of methane background mixing ratio of $2 \mathrm{ppm}$ in the night time up to $4000 \mathrm{~m}$ with $100 \mathrm{~m}$ height and 1 hour temporal resolution. Enhancement of $\mathrm{CH} 4$ mixing ratio inside the boundary layer comparing to the free troposphere values was observed.
\end{abstract}

\section{INTRODUCTION}

Methane is currently the second (after carbon dioxide) most important greenhouse gas of anthropogenic origin. Methane is emitted from a variety of natural and anthropogenic sources (e.g. $[1,2]$ and references therein) and on a permolecule basis, methane is about 30 times more effective a greenhouse gas than carbon dioxide. Existing methane DIAL systems operate in the shortwave infrared (SWIR) spectral range between 1.65 and $2.3 \mu \mathrm{m}$, and due to low Raleigh scattering, methane profiling is possible only inside regions containing significant amounts of aerosol. Raman lidars, by contrast, can operate in aerosol free atmosphere.

Monitoring of the background $\mathrm{CH}_{4}$ concentrations in the troposphere with airborne Raman lidar, based on powerful XeF laser, was reported by Heaps and Burris in 1996 [3]. However, the wideband radiation of excimer lasers requires the use of wideband interference filters in Raman channel, which, in turn, increases the sky background noise and possible contribution of aerosol fluorescence. Wideband detection also creates an additional complication related to interference from the oxygen Raman overtone (second Stokes shift). Significant progress in the development of the interference filters, detectors and laser sources during the last two decades provides, now the opportunity to develop the $\mathrm{CH}_{4}$ Raman lidar based on a relatively compact tripled Nd:YAG laser. For narrowband $354.7 \mathrm{~nm}$ laser radiation the vibrational Raman line of methane is at 395.7 nm, while the oxygen Raman overtone (3089 $\mathrm{cm}^{-1}$ ) is at $398.4 \mathrm{~nm}$, which can be rejected by the interference filter.

In our presentation, we provide the first results of methane profiling in the lower troposphere using LILAS Raman lidar from Lille University observatory platform.

\section{EXPERIMENTAL SETUP}

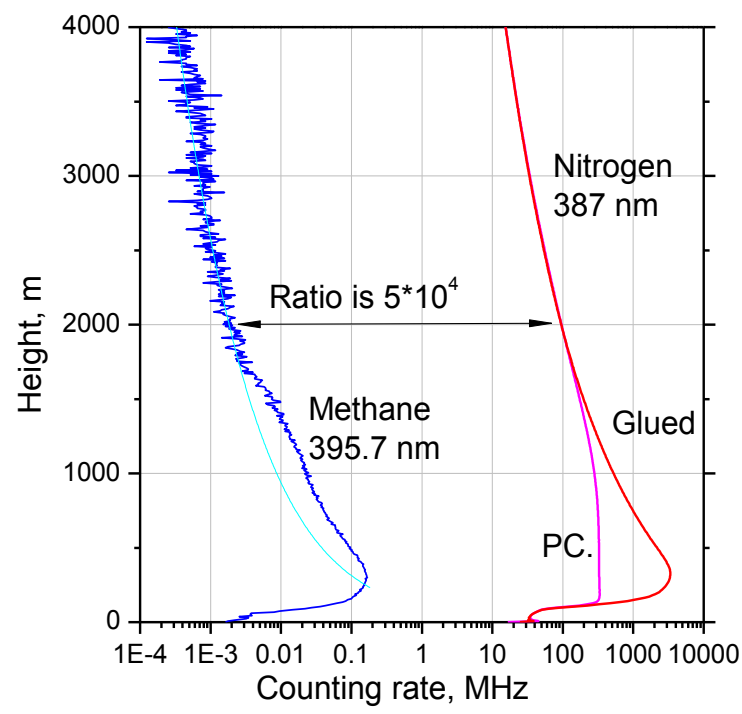

Figure 1. Raman signals corresponding to nitrogen (386.7 $\mathrm{nm})$ and methane (395.7 $\mathrm{nm})$ Raman scattering measured in June 2018. Signals accumulation time is 4 hours. Cian line corresponds to molecule scattering. In nitrogen channel the analog and photon count (PC) signals are glued.

The experiments were performed using multiwavelength Mie-Raman lidar from the Lille University (LILAS). The backscattered light is collected by a $40-\mathrm{cm}$ aperture Newtonian telescope and the outputs of the detectors are 
digitized using Licel transient recorders that incorporate both analog and photon-counting electronics. To perform $\mathrm{CH}_{4}$ measurements shown in this paper, we modified the water vapor channel: $408 \mathrm{~nm}$ interference filter was replaced by the methane filter centered at 395.7 $\mathrm{nm}$. The dichroic mirror in the receiver did not provide efficient selection of the methane (395.7 nm) Raman component, so it was replaced by the mirror with high reflectance at $395.7 \mathrm{~nm}$. Only a small portion of the $387 \mathrm{~nm}$ component was transmitted to the nitrogen channel, while more than $95 \%$ of the $395.7 \mathrm{~nm}$ signal was reflected to the methane channel. Comparing nitrogen Raman backscatter intensity before and after the modification we find that the sensitivity of the $387 \mathrm{~nm}$ channel was degraded by a factor of 185 .

The Alluxa interference filter in the methane Raman channel has a bandwidth of $0.3 \mathrm{~nm}$ with peak transmission greater than $80 \%$. Suppression of 355 and $532 \mathrm{~nm}$ radiation is specified to be greater than 12 orders of magnitude. The Raman scattering cross section of methane is about 8 times higher than that of nitrogen, so for a $2 \mathrm{ppm}$ methane concentration the ratio of intensities of Raman nitrogen to methane scattering is about $5^{*} 10^{4}$. Thus not only should the elastic backscatter components of the signal be suppressed sufficiently, but also the nitrogen and oxygen Stokes and anti-Stokes Raman lines should be as well. To eliminate the possible contribution of rotational anti-Stokes lines, the interference filter was combined with a notch filter, providing an additional OD4 blocking in the $348-360 \mathrm{~nm}$ range.

Two measurement sessions were organized. During the first session in May-June 2018, a flash lamp tripled Nd:YAG laser with a $20 \mathrm{~Hz}$ repetition rate, and pulse energy of $70 \mathrm{~mJ}$ at 355 $\mathrm{nm}$ was used. During second session in December 2018, it was replaced by the Merion MW 9-100 laser with a $100 \mathrm{~Hz}$ repetition rate, and pulse energy of $200 \mathrm{~mJ}$ at $355 \mathrm{~nm}$. The results of first session were recently published in [4].

Fig. 1 shows $\mathrm{CH}_{4}$ and $\mathrm{N}_{2}$ Raman lidar signals on the night of 14-15 June 2018. Aerosols are mainly located below $1700 \mathrm{~m}$, in the same height range the methane backscatter is enhanced in respect to molecule profile. The ratio of nitrogen to methane lidar signals above the PBL top, estimated from our measurements of $5^{*} 10^{4}$, agrees well with prediction, which confirms that we observed methane Raman scattering.
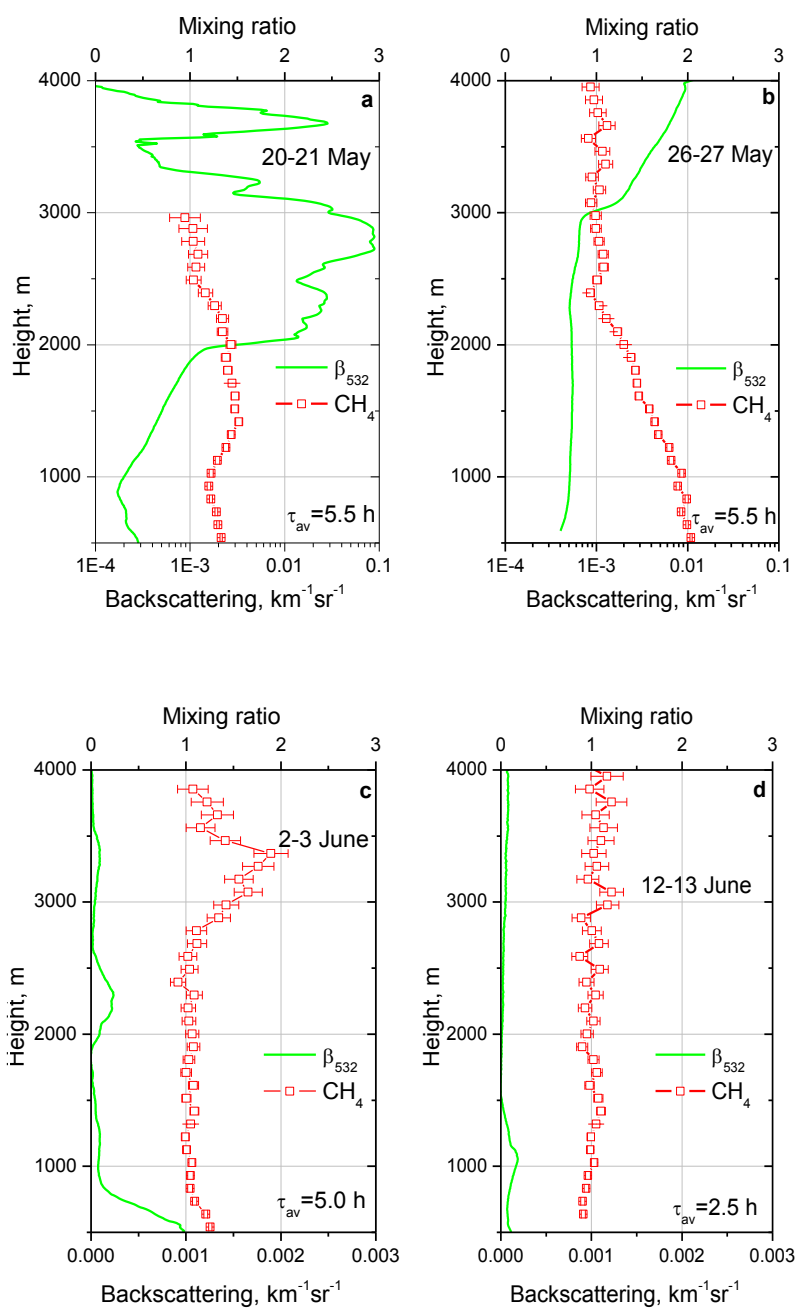

Figure 2. Vertical profiles of the methane mixing ratio and aerosol backscattering at $532 \mathrm{~nm}$ for four night measurement sessions. Mixing ratios are not calibrated and the value 1.0 corresponds to approximately 2 ppm. Signals averaging time $\tau_{a v}$ is given in hours.

\section{RESULTS OF THE MEASUREMENTS}


The lidar derived mixing ratio of methane can be calculated from the ratio of $\mathrm{CH}_{4}$ and $\mathrm{N}_{2}$ lidar signals, corrected for the aerosol and molecular differential extinction.

The derived methane profiles exhibited strong night to night variation. Fig. 2 shows the results of four measurement sessions, representing nights with different aerosol loading. The profiles of the methane mixing ratio are averaged over $100 \mathrm{~m}$ height bins. The same figure provides the profile of the backscattering coefficient at $532 \mathrm{~nm}$. The mixing ratio is given in arbitrary units, assuming that the value of 1.0 corresponds to $n_{\mathrm{CH}_{4}}=2 \mathrm{ppm}$.

On the night of 20-21 May a scattering layer with peak value $\beta_{532}=0.09 \mathrm{~km}^{-1} \mathrm{sr}^{-1}$ occurs in the $2500-$ $3100 \mathrm{~m}$ height range. Low lidar ratio (below 20 sr) and low depolarization ratio (below 5\%) indicate that this layer is likely a water cloud. Strong cloud scattering demonstrates no influence on the mixing ratio, which is about 1.0 in the center of the cloud, proving that the interference filters provide sufficient rejection of elastic scattering. It should be mentioned also that the Raman band of the liquid water extends from 395 $\mathrm{nm}$ to $409 \mathrm{~nm}$, so potentially it can be an interfering factor in the methane measurements. However, Fig.2a does not reveal a noticeable effect of liquid water Raman scattering on the methane profile due to the narrowband filter in the $\mathrm{CH}_{4}$ channel. Cloud layers occurred also on 26-27 May (Fig.2b) at a height of approximately $4000 \mathrm{~m}$ with maximum values of backscattering coefficients of $\beta_{532}=0.01 \mathrm{~km}^{-1} \mathrm{sr}^{-1}$. As in Fig.2a, the presence of clouds does not influence the methane measurements. By contrast, the night of 12-13 June (Fig.2d) was characterized by a low aerosol backscattering coefficient in the $500-4000 \mathrm{~m}$ range $\left(\beta_{532}\right.$ is below $\left.2 * 10^{-4} \mathrm{~km}^{-1} \mathrm{sr}^{-1}\right)$ and the mixing ratio shows no significant deviation from the 1.0 value in the whole height range. On 2-3 June, the increase of $\mathrm{CH} 4$ mixing ratio at $3400 \mathrm{~m}$ correlates with a weak aerosol layer $\left(\beta_{532}<10^{-4} \mathrm{~km}^{-}\right.$ $\left.{ }^{1} \mathrm{Sr}^{-1}\right)$ at the same height. It is interesting that a stronger aerosol layer at $2300 \mathrm{~m}$ is not accompanied by an increase in $n_{\mathrm{CH}_{4}}$.

The use of powerful DPSS laser during session in December 2018 allowed to reduce the uncertainties of the measurements, as follows from Fig.3, showing nitrogen and methane Raman lidar signals on 25-26 December 2018. The DPSS laser allows to profile the methane mixing ratio with 1 hour resolution. Fig. 4 presents twelve $\mathrm{CH}_{4}$ profiles collected during the night 26-27 December for period 18:00 - 06:00 UTC. Statistical uncertainties are given for the first profile only (for the rest of profiles the uncertainties are similar). This figure demonstrates that profiling up to $4000 \mathrm{~m}$ with 1 hour resolution is possible. The time series of the methane ratio for three height intervals are given by Fig.5. The temporal variations of $\mathrm{CH}_{4}$ exceed estimated statistical uncertainties.
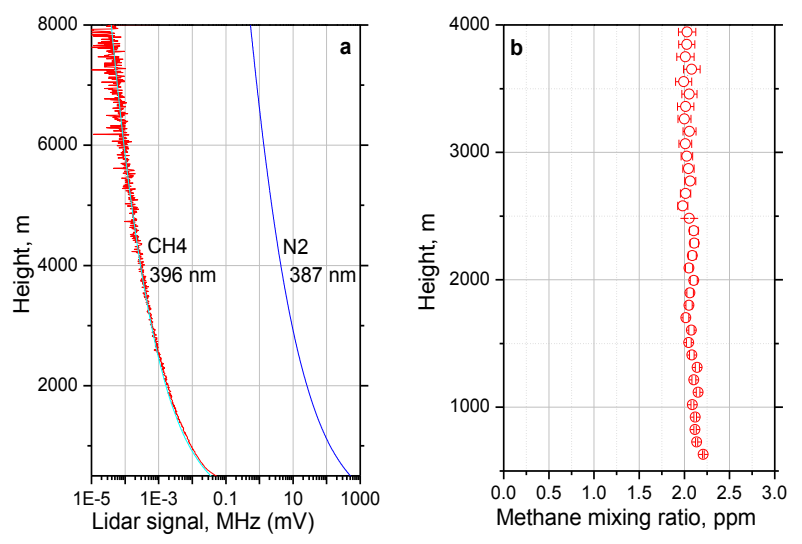

Figure 3. Raman lidar signals on 25-26 December 2018 corresponding to $\mathrm{N}_{2}$ and $\mathrm{CH}_{4}$ together with methane mixing ratio obtained with DPSS laser. Averaging time is 7 hours.

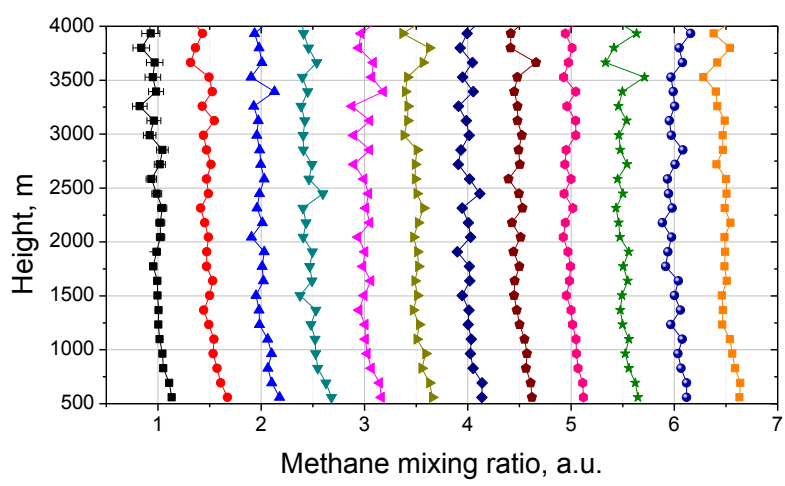

Figure 4. Vertical profiles of methane mixing ratio measured on the night 26-27 December 2018 for period 18:00 - 06:00 UTC. Profiles are averaged for 1 hour and shifted relatively to each other by 0.5. Mixing ratios are not calibrated and the value 1.0 corresponds to approximately 2 ppm.

\section{CONCLUSIONS}


The results presented here demonstrate the feasibility of profiling the background mixing ratios of methane in the lower troposphere using Raman lidar. In our measurements we observed enhanced concentrations of the methane inside the $\mathrm{PBL}$, compared to aerosol free regions. The $\mathrm{CH}_{4}$ profiles are not always correlated with aerosol backscattering, which corroborates the hypothesis that, in the PBL, not aerosol fluorescence but methane is measured. However, we cannot completely exclude fluorescence contribution. To measure and correct for it, if necessary, we plan to introduce an additional control channel close to $393 \mathrm{~nm}$ where no strong Raman lines exist and only fluorescence can be detected. Raman lidars for $\mathrm{CH}_{4}$ monitoring cannot compete with IR airborne DIAL systems in sensitivity and accuracy. However, Raman lidars are capable to evaluate the vertical profile of methane concentrations through the boundary layer and in the aerosol free atmosphere.

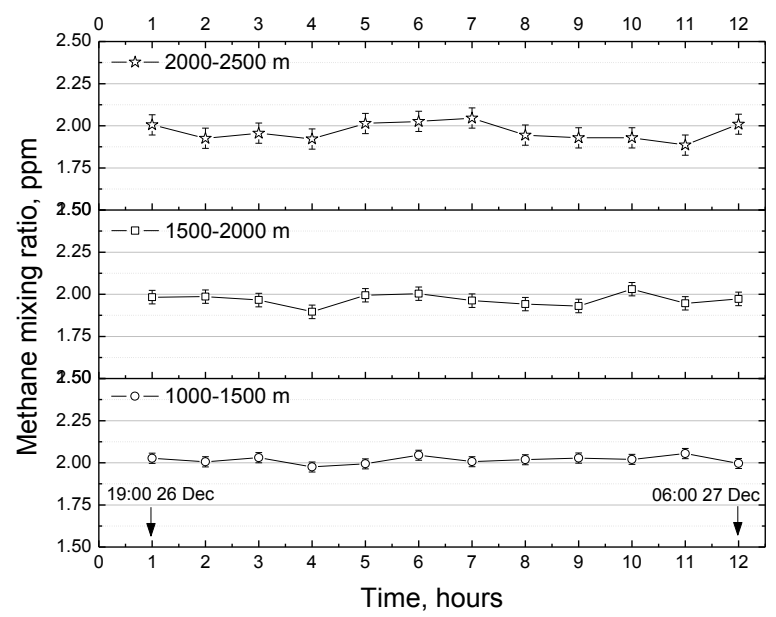

Figure 5. Time series of the methane mixing ratio in the height layers of $1000-1500 \mathrm{~m}, 1500-2000 \mathrm{~m}$, 2000 - $2500 m$ measured on on the night 26-27 December 2018. Averaging time is 1 hour.

\section{ACKNOWLEDGEMENTS}

We acknowledge Emilie Colin and Melody Lardier from Lumibird, the new name of the QUANTEL-KEOPSYS group, for providing a Merion MW 9-100 laser and technical support. Development of the software for lidar data analysis was supported by the Russian Science Foundation (project no.16-17-10241).

\section{References}

[1] Baray, S., et al.: Quantification of methane sources in the Athabasca Oil Sands Region of Alberta by aircraft mass balance, Atmos. Chem. Phys., 18, 7361-7378, 2018.

[2] Kavitha, M., Nair, P. R.: Non-homogeneous vertical distribution of methane over Indian region using surface, aircraft and satellite based data, Atmospheric Environment 141, $174-185,2016$.

[3] Heaps, Wm. S. and Burris, J.: Airborne Raman lidar, Appl. Opt. 35, 7128-7135, 1996.

[4] Veselovskii, I., Goloub, P., Hu, Q., Podvin, T., Whiteman, D. N., Korenskiy, M., Landulfo, E.: Profiling of $\mathrm{CH} 4$ background mixing ratio in the lower troposphere with Raman lidar: a feasibility experiment., Atmos. Meas. Tech., 2019. 